\title{
HTS POWER LEAD TESTING AT THE FERMILAB MAGNET TEST FACILITY
}

\author{
R. Rabehl, R. Carcagno, S. Feher, Y. Huang, D. Orris, Y. Pischalnikov, \\ C. Sylvester, and M. Tartaglia \\ Fermi National Accelerator Laboratory \\ Batavia, Illinois, 60510, USA
}

\begin{abstract}
The Fermilab Magnet Test Facility has tested high-temperature superconductor (HTS) power leads for cryogenic feed boxes to be placed at the Large Hadron Collider (LHC) interaction regions and at the new $\mathrm{BTeV} \mathrm{C0}$ interaction region of the Fermilab Tevatron. A new test facility was designed and operated, successfully testing 20 pairs of HTS power leads for the LHC and 2 pairs of HTS power leads for the BTeV experiment. This paper describes the design and operation of the cryogenics, process controls, data acquisition, and quench management systems. Results from the facility commissioning are included, as is the performance of a new insulation method to prevent frost accumulation on the warm ends of the power leads.
\end{abstract}

KEYWORDS: Test facilities, power leads, HTS, thermal insulation

PACS: 07.20.Mc, 84.71.-b

\section{INTRODUCTION}

At each of the four interaction regions in CERN's LHC, high-gradient quadrupole magnets will focus the proton beams into collision. HTS power leads have been integrated into cryogenic end boxes and will power the eight magnet cold masses at each interaction region. Twenty pairs of these $7.5 \mathrm{kA}$ HTS power leads have been manufactured.

An existing test facility at the Fermilab Magnet Test Facility was redesigned, rebuilt, commissioned, and operated to test these LHC HTS power leads. This facility was previously used to test Tevatron HTS power leads [1]. Redesigned but retaining this capability in anticipation of testing HTS power leads for the BTeV experiment, the facility includes cryogenics, process controls, data acquisition, and quench management subsystems. All twenty pairs of LHC HTS leads and two pairs of BTeV HTS leads were 
cold tested in this facility. The facility subsystems and their operation are described here along with commissioning results.

A method for insulating the warm end of power leads to prevent frost accumulation was developed during testing of the $\mathrm{BTeV}$ power leads. The scheme and its performance are described.

\section{CRYOGENICS SYSTEM AND OPERATIONS}

\section{LHC HTS Lead Testing}

The HTS leads test facility is a stand-alone facility; cryogenic fluids are not supplied by the Magnet Test Facility 1500 W refrigerator. Portable dewars supply both liquid helium and liquid nitrogen.

FIGURE 1 shows the top plate assembly with two power leads installed. The top plate assembly was supplied by CERN. The top plate is fabricated from $2.5 \mathrm{~cm}$ thick stainless steel. Two lead chimneys are built into the top plate at a $10^{\circ}$ angle to match the orientation of the leads when installed in a cryogenic feed box. A copper gasket seal is used at the upper end of each chimney, and a polyether ether ketone (PEEK) seal is used at the lower end of each chimney. A $5 \mathrm{~cm}$ thick closed cell foam baffle and five $0.16 \mathrm{~cm}$ thick aluminum baffles with multilayer insulation are supported from the top plate and minimize the radiation heat load to the $4.5 \mathrm{~K}$ helium bath. Helium gas at $20 \mathrm{~K}$ is supplied to the power leads through a top plate bayonet connection and an insulated $2.5 \mathrm{~cm}$ tube. A second bayonet connection vents boiloff from the test dewar $4.5 \mathrm{~K}$ bath. After the power leads are installed, additional fixtures are mounted to support temperature sensors, liquid level probes, and a splice block.

The test dewar was fabricated by Cryofab. It has a $51 \mathrm{~cm}$ inner diameter and is $107 \mathrm{~cm}$ deep. The dewar contains $100 \mathrm{l}$ of liquid at normal test conditions for the LHC HTS power leads.
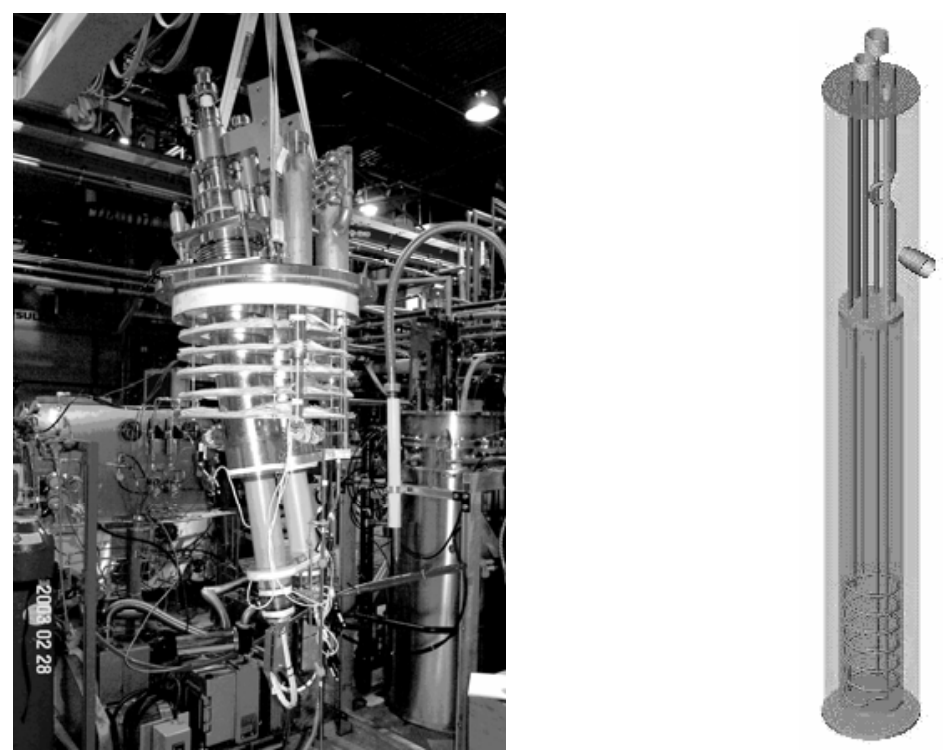

FIGURE 1. The picture on the left shows the insert with two installed power leads being readied to place in the test dewar. The picture on the right shows the phase separator used to supply helium gas to the power leads. 
A simplified flow schematic for testing the LHC HTS power leads is shown in FIGURE 2. A $500 \mathrm{l}$ helium dewar supplies the test dewar bath. A proportional-integral (PI) control loop uses the test dewar liquid level L1 as the process variable to control the liquid supply valve V1 and maintain a constant liquid level in the test dewar. A second 5001 helium dewar supplies the helium flow required to cool and maintain the HTS warm terminals at $50 \mathrm{~K}$. Liquid helium from the portable dewar is transferred into a phase separator. The phase separator is a small, vacuum-jacketed helium vessel and is shown in FIGURE 1. There are six penetrations in the phase separator top plate for the liquid helium supply, the cold helium gas withdrawal, a relief valve and vent, a liquid level probe, a cartridge heater, and a temperature sensor. A $50 \mathrm{~W}$ cartridge heater J2, controlled by a PI loop-driven SCR power controller, is immersed in the phase separator helium bath to maintain a constant $30 \mathrm{~cm}$ of liquid in the phase separator as measured by liquid level probe L2. The boiloff produced by this heater is taken from the top of the phase separator and recooled by the accumulated liquid before continuing into the downstream transfer line. There, the gas is warmed to $20 \mathrm{~K}$ by heater J3 built into the transfer line. The transfer line heater is a copper block with a $200 \mathrm{~W}$ cartridge heater and multiple holes through which the gas flows and as it is heated. A PI loop, using the gas temperature T3 as the process variable, interfaces with a second SCR power controller to control the cartridge heater.

Mass flow controllers F4 and F5 regulate flows of up to $0.8 \mathrm{~g} / \mathrm{s}$ of $20 \mathrm{~K}$ helium gas to each power lead. For each lead, a PI loop uses the warm terminal temperature T4 or T5 as the process variable. The minimum required pressure drop across these mass flow controllers is $69 \mathrm{kPa}$ (10 psid), but the upstream pressure is limited by the relief valve setting on the $500 \mathrm{l}$ helium dewar. Therefore, the pressure downstream of the mass flow controllers is reduced using two Edwards ED660 mechanical vacuum pumps. With 39 $\mathrm{m}^{3} / \mathrm{hr}(23 \mathrm{cfm})$ of displacement apiece, these pumps were sized to maintain the required pressure drop across the mass flow controllers at the expected $20 \mathrm{~K}$ helium flow rate.

The upper ends of the power leads are maintained frost-free using $400 \mathrm{~W}$ bolt-on heaters J6 and J7. These heaters have built-in thermostats for control.

A final PI loop controls the liquid nitrogen supply to the test dewar thermal shield. When temperature sensor T8 reaches $100 \mathrm{~K}$, solenoid valve V8 is opened for $10 \mathrm{~s}$ to refill the shield bath.

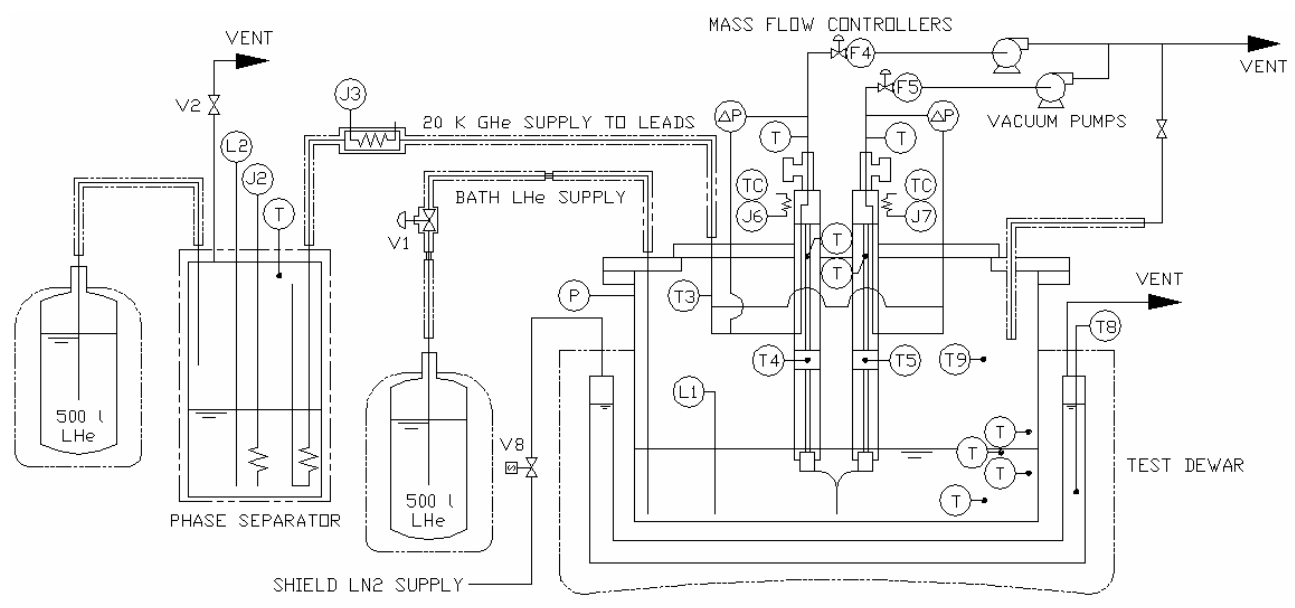

FIGURE 2. Simplified flow schematic for LHC HTS lead testing. 


\section{Facility Commissioning with LHC HTS Leads}

Commissioning of the test facility began in March 2003 with the first pair of production power leads. A significant problem encountered was that the temperature of the nominally $20 \mathrm{~K}$ gas supplied to the HTS warm terminals was very unsteady due to twophase flow, oscillating by 10-15 K. The portable dewar stinger was raised above the liquid level so that only cold gas would be transferred. This made the system control somewhat labor intensive, but the lead flow supply temperature was much steadier. Designing the phase separator and incorporating it into the system in time to test the third pair of production leads in June 2003 solved this problem. The phase separator allows helium gas over a wide temperature range to be supplied to the power lead warm terminals. Lead flow supply temperatures as low as 6-8 K were achieved by turning off the transfer line heater and increasing the mass flow rate.

An important finding from the commissioning of the test facility was that the elevation at which helium boiloff was vented from the test dewar had a significant impact on power lead performance. The vacuum-jacketed bayonet for venting helium boiloff initially extended to the elevation of the warm terminals. Each power lead required $0.50 \mathrm{~g} / \mathrm{s}$ of helium to maintain a $50 \mathrm{~K}$ warm terminal with no current. While powered at $7500 \mathrm{~A}$, over $0.6 \mathrm{~g} / \mathrm{s}$ was required by each power lead to maintain $70 \mathrm{~K}$ at the warm terminal. A $50 \mathrm{~K}$ warm terminal temperature could not be maintained, and the Edwards mechanical vacuum pumps were struggling to maintain the required pressure differential across the mass flow controllers. This limited the achievable lead flow rates, and the warm terminal temperature rose to $70 \mathrm{~K}$ as a result. It was expected that $0.4-0.5 \mathrm{~g} / \mathrm{s}$ through each power lead would be required at $7500 \mathrm{~A}$ to maintain $50 \mathrm{~K}$ at the warm terminal. The vacuum-jacketed vent bayonet was shortened by $20 \mathrm{~cm}$ so that boiloff was removed at a higher elevation. The resulting lead flows at zero current were greatly reduced, from $0.50 \mathrm{~g} / \mathrm{s}$ to $0.14 \mathrm{~g} / \mathrm{s}$ per lead. Similarly, at $7500 \mathrm{~A}$, the lead flows were reduced to $0.44 \mathrm{~g} / \mathrm{s}$ per lead. A $50 \mathrm{~K}$ warm terminal temperature could also be maintained under these conditions. The effect of the vent elevation was also seen on temperature sensor T9, located at the same elevation as the HTS warm terminals as indicated in FIGURE 2. This temperature sensor read $15 \mathrm{~K}$ during steady operation with the long vent bayonet. With the short vent bayonet, this temperature sensor reading dropped to $8 \mathrm{~K}$ during steady operation due to reduced stratification of the helium gas surrounding the power lead chimneys.

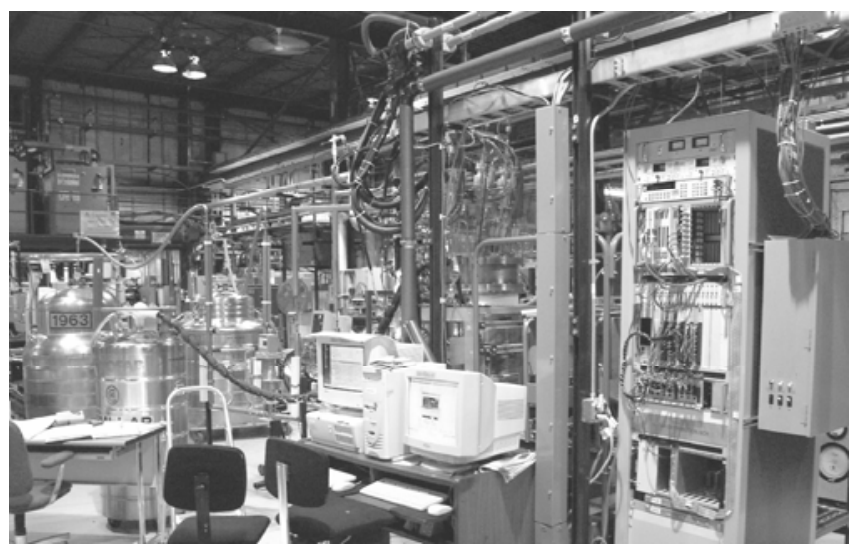

FIGURE 3. A view of the LHC HTS power lead test system in operation. 
Commissioning of the new test facility was concluded after seven weeks with a successful cold test of the first pair of production power leads in late April 2003. Seventeen $500 \mathrm{l}$ helium dewars were used to commission the test facility.

FIGURE 3 shows the test facility in operation. At the left are two $500 \mathrm{l}$ liquid helium dewars and one $240 \mathrm{l}$ liquid nitrogen dewar. At the center are two personal computers for monitoring and controlling the facility. The test dewar is behind the computers, and the power bus and flexible power leads can be seen overhead. The instrumentation rack to the right contains power supplies, liquid level instrumentation, quench detection hardware, PLC system hardware, temperature transmitter cards, and heater controllers.

Cold testing of the final pair of production LHC HTS power leads was completed in March 2005. A detailed description of the test plan and production test results are described elsewhere [2]. Eighty-one helium dewars were used to complete the testing of the 20 pairs of leads. Liquid usage and boiloff rates indicated heat loads of $18 \mathrm{~W}$ in the transfer lines supplying the test dewar and $6 \mathrm{~W}$ to the bath due to conduction down the power leads and conduction and radiation heat loads on the helium vessel.

\section{BTeV HTS Lead Testing}

During pauses in the LHC HTS power lead test program, two pairs of American Superconductor Corporation (ASC) HTS power leads used for Fermilab Tevatron spool pieces were cold tested at $10 \mathrm{kA}$ for the now-cancelled $\mathrm{BTeV}$ experiment. Details of the test program and results can be found elsewhere [3].

A second, existing dewar insert is used when testing ASC HTS power leads. This top plate is made from $1.9 \mathrm{~cm}$ thick stainless steel. A baffle system of closed cell foam and copper-clad G-10 plates is used. An arrangement of liquid level probes and temperature sensors in the test dewar bath similar to that employed for LHC HTS lead testing is also used.

A simplified flow schematic for testing the ASC HTS power leads is shown in FIGURE 4. Again, a $500 \mathrm{l}$ helium dewar supplies the test dewar bath with liquid level control using liquid supply valve V1 with the liquid level probe L1 providing the process variable.

A second helium dewar and the phase separator are not needed when testing ASC HTS power leads. Instead, a liquid nitrogen dewar is required to provide $80 \mathrm{~K}$ cooling to the HTS warm terminals. The liquid nitrogen flow rate to each power lead is controlled by the downstream mass flow controller. In this testing mode, the mass flow controllers are not operated as part of a control loop. They are instead operated in a manual mode to meet the requested mass flow rate.

Two mass flow meters were added to the system to measure the small amount of helium boiloff required by the leads to cool the HTS sections.

The Edwards mechanical vacuum pumps downstream of the mass flow controllers are not required when testing ASC HTS leads. The liquid nitrogen supply dewar is typically operated at $103.4 \mathrm{kPa}(\mathrm{g})(15 \mathrm{psig})$, so maintaining a $69 \mathrm{kPa}(10 \mathrm{psi})$ differential pressure across the mass flow controllers is not a problem. 


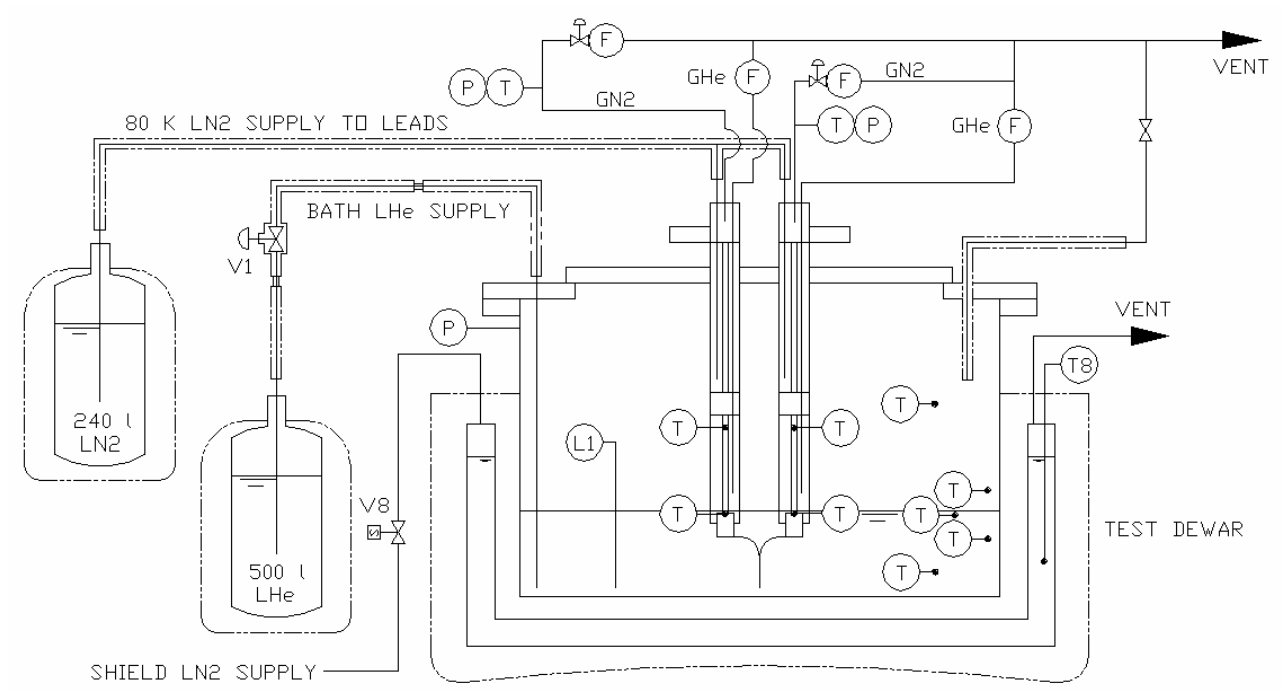

FIGURE 4. Simplified flow schematic for testing ASC HTS power leads.

\section{TEST FACILITY CONTROL SYSTEM}

The test facility control system follows the architecture of the Magnet Test Facility (MTF) $1500 \mathrm{~W}$ refrigerator control system [4]. However, the test facility control system has a separate programmable logic controller (PLC) and shares a supervisory control and data acquisition (SCADA) node with an LHC quadrupole horizontal test stand. As a standalone facility, operation of the test facility is unaffected by refrigerator operations. The test facility control system is also independent from the data acquisition (DAQ) and quench management systems so that cryogenic operability is maintained in the event of reconfiguration or failures of these systems. The operator interface software provides easy navigation between refrigerator control displays and test facility control displays, real-time and historical trending, an alarm management system, and first-fault diagnostics displays to help quickly identify and troubleshoot problems. Power supply interlocks prevent the power system from turning on if an unsafe condition exists, such as insufficient water flow through the power buswork. A software link provides two-way communication between the test facility control system database and the DAQ system.

\section{TEST FACILITY DATA ACQUISITION SYSTEM}

The test facility DAQ system follows the standard DAQ architecture used at the Fermilab Magnet Test Facility. Its main function is to provide accurate four-wire measurements of devices, such as temperature sensors, at a relatively low sampling frequency ( $\sim$ channels/s). Details of the DAQ system have been described elsewhere [5].

\section{TEST FACILITY QUENCH MANAGEMENT SYSTEM}

The quench management system monitors and controls the power lead protection hardware, provides permits for the power system to turn on, and monitors the power leads for resistive voltages (quench detection) [6] above the threshold. Typical thresholds are 100 
$\mathrm{mV}$ on the copper section, $1 \mathrm{mV}$ on the HTS section, $1 \mathrm{mV}$ across the copper-HTS connection, and $1 \mathrm{mV}$ across the HTS-LTS connection. The voltages are digitized and integrated over a line cycle by two instruments: a Hewlett Packard 3458A digital voltmeter for the data acquisition system, and a Pentek data logger for the quench management system. When a quench is detected, the quench management system carries out the necessary actions in order to shut down the power supplies while logging power lead voltage data at a fast rate in order to characterize the quench.

\section{POWER LEAD THERMAL INSULATION}

Unlike the LHC HTS power leads, the BTeV HTS leads do not have bolt-on heaters to prevent the formation of frost on the tops of the leads. Insulation methods were explored as a means to prevent frost using a passive, robust solution. Two-part polyurethane spray foam was considered a good candidate. It is readily available, easy to apply, and easy to work with once it has cured.

A mockup was fabricated to investigate whether this material would work for this application. The mockup simulated the geometry of ASC HTS leads as they are installed in Tevatron spool pieces. A SiCoat 570 (CSL Silicones, Inc.; Guelph, ON, Canada) silicone coating used on HTS power leads installed in Tevatron spool pieces was applied to the mockup to verify that the foam would adhere to this surface. Forms were fabricated from sheet metal to define the final shape of the foam, and mold release agent was applied to the forms to minimize adhesion to the foam. Areas not to be foamed, such as gas connections and the power lead flags, were masked off. Two thermocouples were mounted on the mockup: the first between the simulated leads at their base, the second just below the simulated lead flags. The foam was then applied and left to cure overnight. The forms were removed the next day and the foam shaped using a simple blade. The foam proved to adhere well to the silicone coating of the mockup, but it could be removed without too much difficulty. The foam was easy to shape and was found to be quite uniform in density. Fast expansion of the foam as it was sprayed prevented the formation of large voids within the foam. Two coats of silicone were then applied to the foam.

The thermal performance of the foam was next studied. In the mockup, provisions were made in the simulated power leads for a flow of cold nitrogen. The thermocouples were monitored as cold nitrogen gas was passed through the mock leads. Temperatures under the foam near the lead flags reached $-60 \mathrm{C}$, but the foam surface remained warm enough to prevent frost. The surface temperature was measured to be about $10 \mathrm{C}$ using an infrared thermometer.

The mockup was successfully hipotted under both warm and cold conditions with only a few hundredths of a microampere of leakage current at $5 \mathrm{kV}$.

The insulation was next applied to a pair to ASC HTS leads to be tested in the HTS leads test facility. During standby operations with $1.2 \mathrm{~g} / \mathrm{s}$ N2/lead and $0.02 \mathrm{~g} / \mathrm{s} \mathrm{He} / \mathrm{lead}$, the foam surface temperature was measured to be $10 \mathrm{C}$ with an infrared thermometer. Previous cold tests with non-insulated warm ends had measured lead warm end temperatures of -40 C.

This insulation method was deemed successful and has been implemented on two Tevatron spool pieces with installed ASC HTS power leads. These spool pieces are expected to be installed in the Tevatron during the upcoming November 2005 shutdown. 


\section{CONCLUSIONS}

A new facility for testing HTS power leads has been in operation at the Fermilab Magnet Test Facility since March 2003. Cold testing of 20 pairs of HTS power leads for the LHC interaction region feed boxes has been completed, as has testing of two pairs of HTS power leads for the Fermilab BTeV experiment.

A new insulation method for power lead warm ends has been successfully developed and will soon be implemented at the Fermilab Tevatron.

\section{ACKNOWLEDGMENTS}

The technical staff of Fermilab’s Magnet Test Facility completed all aspects of the test facility construction and operation, and their expertise and experience resulted in successful completion of the test programs. This work is supported by the U.S. Department of Energy under contract No. DE-AC02-76CH03000.

\section{REFERENCES}

1. Citver, G., Feher, S., Limon, P. J., Orris, D., Peterson, T., Sylvester, C., Tartaglia, M. A., and Tompkins, J. C, "HTS power lead test results," in Proceedings of the 1999 IEEE Particle Accelerator Conference, edited by A. U. Luccio and W. W. MacKay, IEEE, Piscataway, NJ, 1999, pp. 1420-1422.

2. Tartaglia, M. A., Carcagno, R. H., Feher, S., Huang, Y., Orris, D. F., Pischalnikov, Y., Rabehl, R. J., Sylvester, C., and Zbasnik, J., "Production LHC HTS Power Lead Test Results,” in IEEE Transactions on Applied Superconductivity Volume 15 Number 2, edited by J. W. Spargo et al., IEEE, New York, 2005, pp. 1500-1503.

3. Feher, S., Carcagno, R., Orris, D., Page, T., Pischalnikov, Y., Rabehl, R., Sylvester, C., Tartaglia, M., and Tompkins, J. C., "HTS Power Leads For The BTeV Interaction Region,” in Proceedings of the 2005 IEEE Particle Accelerator Conference, to be published.

4. Carcagno, R.H. and Rabehl, R.J., "Controls Upgrade of the Fermilab Magnet Test Facility $1500 \mathrm{~W}$ Helium Refrigerator,” in Advances in Cryogenic Engineering 45B, edited by Q. Shu et al., Plenum, New York, 2000, pp.1795-1802.

5. Carcagno, R. and Orris, D., "A Modular and Extensible Data Acquisition and Control System for Testing Superconducting Magnets," in Proceedings of the 2001 IEEE Particle Accelerator Conference, edited by P. Lucas and S. Webber, IEEE, Piscataway, NJ, 2001, pp. 3463-3465.

6. Orris, D.F., Feher, S., Lamm, M.J., Nogiec, J., Sharonov, S., Tartaglia, and Tompkins, M. J., "A Digital Quench Detection System for Superconducting Magnets," in Proceedings of the 1999 IEEE Particle Accelerator Conference, edited by A. U. Luccio and W. W. MacKay, IEEE, Piscataway, NJ, 1999, pp. 3191-3193. 